\title{
BLUE JAY CHATTER
}

\section{EDUCATION FOR PROTECTION}

Now that hawks, owls and eagles are legally protected by newly-enacted legislation the complete text is presented on p.p. 127) it might be assumar that we need merely wait a few seasons to see an increase in the numbers of these birds. This could happen if the public were aware of the new laws. Unfortunately, no one outside of those concerned with the introduction of these laws seems to have heard of them. Members of the Saskatchewan Falconry Associaticn have disappointedly reported having seen as many dead hawks as ever fastented like ill omens to fences throughout the country. Obviously there is an immediate nsed for publicity beycnd what we have already undertaken. Every member of our society can assist in acquainting the public with these laws and with the reasons for their enactment. Our executive is considering further means of publicity but personal efforts by each of us will always be needed and useful. This will have to be a continuous program, but it is just the kind of activity to which our society is dedicated. "Did you know that hawks and owls are now legally protected ... . ?" may not seem like a good opening for an after-dinner converiation, but our experience has taught us that many persons not especially interested in birds are interesited in hawks and crwls and that the aspect of legal protection for these species elicits even greater respect for them.

\section{TWELFTH ANNUAL MEETING OF THE SOCIETY}

This year the annual meeting of the Society will again be held in the Saskatchewan Museum of Natural History. We have always appreciated the opportunity to visit the Museum on these occasions and the hospitality extended to our members by the Museum staff. If any of our members have not visited the Museum since the last annual meeting held there three years ago, they will be interested in the developments that have taken place. This will also be an opportunity for our members to meet new members of the Museum staff and to see phoito and film material that has been produced in connection with field work done this past selason by members of the different departments. Our president, Dr. Bob Nero, has just come back from three months' field study at Uranium City and we are looking forward to a report from him and his co-workers and to seeing some of the kodachrome photos of the country and its birdlife.

Special speaker at the annual meeting will be Al Hochbaum, the well known author and artist, who is direcitor of the Delta Waterfowi Research Station. Al Hochbaum was in Regina recently at the Federal-Provincial Wildlife Convention and we are looking forward to seeing this friendly, unassuming wildlife expert again in October.

Our members always look forward to the October meeting as an occasion for friends with similar interests in natural history to get together. This year we hope that many new friends will join our group. We like to think that some new friends have been gained for the Society this summer through our new bookstall at the Museum where we have been selling natural history maiterials to interested visitors. On an experimental basis, the Society undertook to operate the counter every afternoon during the holiday months of July and August. Mrs. Elizabeth Cruickshank has been in charge and she has been meeting the public land representing the Society in her inimitably friendly way (p.145). We hope that this pilot project may help to estabilish a permanent bookshop in the Museum. 